\title{
Saturated Fatty Acids Derivatives as Assistants Materials for Textile Processes
}

\author{
Ahmed G Hassabo*, Sahar Sharaawy and Amina L Mohamed \\ National Research Centre, Egypt
}

*Corresponding author: Ahmed G Hassabo, National Research Centre, Egypt

Received Date: October 30, 2018

Published Date: November 14, 2018

\begin{abstract}
Many auxiliaries have been used in textile industries in dry or wet processes. One of the important based materials is fatty acids and its derivatives. The present work aims at preparing some textile auxiliaries based on saturated fatty acids. Six different materials were used to react with each fatty acid. Produced materials have been characterised using FT-IR, HLB and cloud point. Based on the HLB values, produced materials have been used as softeners or as $0 / \mathrm{W}$ emulsifiers (printing paste). Treated fabrics with softeners show a very good physical and mechanical properties and printed fabrics with prepared pastes shows a good printing paste with good prints characteristics (colour strength and colour fastness).
\end{abstract}

Keywords: Saturated fatty acid, Hydrophilic -Lipophilic Balance, Textile softeners, O/W emulsifiers

\section{Introduction}

A textile auxiliary is chemical or formulated chemical products which enables a processing operation in preparation, dyeing, printing or finishing to be carried out more effectively and/or which is essential if a given effect is obtained [1].

Surfactants or surface-active agents are chemicals, which show ability to adsorb at surfaces [1] it is also known as an agent, soluble or insoluble in a liquid, which reduces the surface tension of this liquid. According to their amphiphilic nature, their molecular structure contains a hydrophobic (non-polar) part and a hydrophilic (polar) part. Surfactants have four main types: anionic, cationic, non-ionic and amphoteric surfactants.

Usually, saturated fatty esters establish a group of valuable synthetic intermediates in the production of a many materials, for example, amides and fatty alcohols. These materials can be used as solvents or softening agent in several fields such as textile, cosmetic, biodiesel and polymer industries $[2,3]$. The esterification of saturated fatty acids normally done using anhydrous alcohols.

Polyethylenimine (PEI) consider as one of the highly effected polymers because it works as shell for several materials. Therefore, it has been utilized in several fields, for example; water purification, paper production and textile softener [4-8]. Due to it is effective properties, its esterified product with saturated and unsaturated fatty acid could be very interesting.
The present research aiming at establishing a base for the preparation and characterization of some textile auxiliaries based on esterification of saturated fatty acid with polyethylene glycol with different molecular weight, octadecylamine, polyethyleneimine or stearyl alcohol. The produced material will be characterised and utilize in textile field depending on their Hydrophilic Lipophilic Balance (HLB) $[1,9,10]$.

\section{Experimental}

\section{Materials}

Three different saturated fatty acid; myristic acid $(228.37 \mathrm{~g} /$ $\mathrm{mol})$, palmitic acid $(256.42 \mathrm{~g} / \mathrm{mol})$ and stearic acid $(284.48 \mathrm{~g} /$ mol). Polyethylene glycol with different molecular weight $(1000,4000$ and $6000 \mathrm{~g} / \mathrm{mol})$, octadecylamine $(269.51 \mathrm{~g} / \mathrm{mol})$, polyethyleneimine $(\cong 60000 \mathrm{~g} / \mathrm{mol})$ and stearyl alcohol $(270.49 \mathrm{~g} /$ mol), urea and diammonium hydrogen phosphate were used as a laboratory grade. Acrylate binder (Helizarin ${ }^{\circledR}$ Binder ETBASF, Egypt) and chloropyrimidine pigment (Drimarine ${ }^{\circledR}$ Blue P, Clariant, Egypt) were used.

\section{Methods}

Reaction of saturated fatty acids: Three saturated fatty acid (namely myristic (MA), palmitic (PA) and stearic (SA) acid) was selected to condensate with different hydroxyl or amino groups 
in different compounds (polyethyleneimine (PEI), octadecylamine (OCTA), stearyl alcohol (SA), and polyethylene glycol (PEG) 1000, 4000 and 6000).

Reaction will be carried out in round flask equipped with Dean and Stark apparatus. 1: 1 mole fatty acids to polymers are melted at $60^{\circ} \mathrm{C}$ and 0.01 mole of sulphuric acid as catalyst was added to the mixture. Then, Danish and Stark apparatus will be fitted onto the flask that introduced into the oil bath. The temperature will then raise to $150^{\circ} \mathrm{C}$ and kept at this temperature to for $5 \mathrm{~h}$, after that the flask will take out from the bath and cooled to room temperature, and the product will be analyzed.

\section{Application of produced materials to cotton fabrics}

Application of produced materials as softeners: Cotton fabric were treated using pad-dry cure technique. Fabric will be padded in the finishing bath consisting of a fatty acid derivative $(10$ 30 or $50 \mathrm{~g} / \mathrm{l}$ ), Hostapal ${ }^{\circledR} \mathrm{CX}$-ET as detergent ( $2 \mathrm{~g} / \mathrm{l}$ ), and acetic acid ( $2 \mathrm{ml} / \mathrm{l}$ ), to a wet pick up of $80 \%$. Blank sample was padded $(100 \%$ wet pick up) in a bath consisting of only Hostapal ${ }^{\circledR}$ CX-ET $(2 \mathrm{~g} / \mathrm{l})$. After that, the blank and treated samples were dried at $100^{\circ} \mathrm{C}$ for 3 min. and cured at $140^{\circ} \mathrm{C}$ for $3 \mathrm{~min}$.

Application of produced materials as emulsifier in printing paste

A printing paste was prepared through emulsifying processusing kerosene in an aqueous solution containing other ingredients materials using a homogenizer. The paste ingredients were as following recipe:

\begin{tabular}{|c|c|}
\hline Colorant & $2 \mathrm{~g}$ \\
\hline Emulsifier & $1.5 \mathrm{~g}$ \\
\hline Kerosene & $65 \mathrm{~g}$ \\
\hline Water & $15 \mathrm{~g}$ \\
\hline Urea & $7 \mathrm{~g}$ \\
\hline Binder & $6 \mathrm{~g}$ \\
\hline Sodium dihydrogen phosphate & $3.5 \mathrm{~g}$ \\
\hline Total & $100 \mathrm{~g}$ \\
\hline
\end{tabular}

Printing was applied to cotton fabrics using the flat screen technique. The prints fabrics were dried at $100^{\circ} \mathrm{C} / 5 \mathrm{~min}$. then cured at $160^{\circ} \mathrm{C} / 3 \mathrm{~min}$.

\section{Characterization of produced materials}

Total conversion percent of the reactants to ester was determined by calculation of the fatty acid amount before and after the reaction. Fatty acid amount was calculating by measuring acid value before and after the reaction $[1,9,11]$.

$$
\text { Total conversion }(\%)=\frac{\left(A_{1}-A_{2}\right)}{\left(A_{1}-A_{c}\right)} \times 100
$$

where $A_{1}$ is the acid value before the reaction, $A_{2}$ is the acid value after the reaction, $A_{c}$ is the acid value of catalyst.

Acid value was determined according the following procedure: [11] 1-5 g of prepared materials was dissolved in $50 \mathrm{ml}$ of ethanol: water (1: 1) (using heat if necessary). $1 \mathrm{ml}$ phenol phethalien was added to the solution, and then titrate against $0.1 \mathrm{~N} \mathrm{KOH}$. Therefore, acid value was calculated using following equation:

$$
\text { Acid value }=\frac{V T \times 1000}{W}
$$

where: $\mathrm{V}$ is volume of $0.1 \mathrm{~N} \mathrm{KOH}$ used in the titration of the sample, $\mathrm{ml}, \mathrm{T}$ is titer of the $\mathrm{KOH}$ solution $\left(\frac{N \times e q . w t}{1000}\right), \mathrm{g} / \mathrm{ml}$, and $\mathrm{w}$ is weight of the sample, grams.

FT-IR spectroscopy for the prepared compounds were done using JASCO FT-IR spectrometer (ATR) with data collection over a total range of $4000-400 \mathrm{~cm}^{-1}$ with best resolution of $0.5 \mathrm{~cm}^{-1}$.

Hydrophilic - Lipophilic Balance (HLB) of the prepared materials was calculated according to the following formula: $[1,9,10,12]$.

$$
H L B=\frac{1}{5} \times\left(\frac{\text { formula weight of the compound }}{\text { formula weight of the hydrophilic part }}\right) \times 100
$$

Cloud point of the prepared materials was calculated as follow: A paste from the product was prepared as following: $5 \mathrm{~g}$ of the product was added to $20 \mathrm{ml}$ ethanol/water (20:80). After that, 1 g paste was dispersed in $100 \mathrm{ml}$ water. Then, it was heated up by $1^{\circ} \mathrm{C} / \mathrm{min}$. until the solution became cloudy at temperature (T1). Then, the temperature was raised over $\mathrm{T} 1$ by $5^{\circ} \mathrm{C}$, and then cooled down with the same rate until the solution become cloudy again (T2). Cloud point was then calculated using the following equation: $[1,9,10,12,13]$.

$$
\text { Cloud point }=\frac{\left(T_{1}+T_{2}\right)}{2}
$$

Dry crease recovery angle (CRA) was measured according to AATCC Test Method 66-1990 [14]. Fabric roughness was measured using Surface Roughness Measuring Instrument SE 1700 a. Fabric stiffness were determined according to ASTM Test Method D 138896E1 using the cantilever apparatus [15]. Wettability was evaluated according to AATCC Test Method 39-(1971) [16].

Colour strength and fastness properties of the printed samples were evaluated by Hunter Lab Ultra Scan PRO (Hunter Lab Ultra Scan PRO (USA, 2007) [4,7,10,17-27].

The colour intensity (E) and the relative colour strength (K/S) of the printed cotton fabrics was measured and assessed by applying the Kubelka-Munk equation as follow [28]:

$$
K / S=\frac{(1-R)^{2}}{2 R}-\frac{\left(1-R_{0}\right)^{2}}{2 R_{0}}
$$

SSwhere $\mathrm{K}$ is the absorption coefficient, $\mathrm{S}$ is the scattering coefficient, Ro is the reflectance of uncolored (white) sample, and R is the reflectance of colored sample.

The colour fastness to washing was determined according to the AATCC Test method 61-1975 using Launder-Ometer. [18] The colour fastness to crocking was determined according to the AATCC test method 8 - 1977 [25]. The colour fastness to perspiration was determined according to the AATCC test method 8 - 1977 [26]. Evaluation of the fastness was established using the Gray Scale reference for colour change. 


\section{Results and Discussion}

\section{Characterization of produced materials}

Total conversion: The results in Table 1 and Figure 1 presented the total conversion percent for the prepared materials with each saturated fatty acid. Percent total conversion is an indication for the ability to produce material. It is indication for the conversion of carboxyl group in fatty acid to ester or amide with hydroxyl or amine group in polyalcohol or polyamine.

Table 1: Total conversion percentage for prepared materials from saturated fatty acids.

\begin{tabular}{|c|c|c|c|}
\hline Fatty acid & & Code & Total Conversion (\%) \\
\hline \multirow{6}{*}{$\begin{array}{c}\text { Stearic acid } \\
(284.49) \\
\mathrm{CH} 3(\mathrm{CH} 2)_{16} \mathrm{COOH} \\
\mathrm{CH}_{3}\left(\mathrm{CH}_{2}\right)_{15} \mathrm{CH}_{2}^{\mathrm{OH}}\end{array}$} & PEG 1000 & SA-1000 & 86.95 \\
\hline & PEG 4000 & SA-4000 & 85.89 \\
\hline & PEG 6000 & SA- 6000 & 85.14 \\
\hline & Stearyl alcohol & SA-Sa & 92.82 \\
\hline & PEI & SA-PEI & 96.83 \\
\hline & Octadecylamine & SA-OCT & 82.98 \\
\hline \multirow{4}{*}{$\begin{array}{c}\text { Palmitic acid } \\
256.43 \\
\mathrm{CH} 3(\mathrm{CH} 2)_{14} \mathrm{COOH}\end{array}$} & PEG 1000 & PA-1000 & 88.04 \\
\hline & PEG 4000 & PA-4000 & 87.03 \\
\hline & PEG 6000 & PA- 6000 & 86.99 \\
\hline & Stearyl alcohol & PA-SA & 93.35 \\
\hline \multirow{2}{*}{$\mathrm{H}_{3} \mathrm{C} \underbrace{\mathrm{O}}_{14} \mathrm{OH}$} & PEI & PA-PEI & 96.99 \\
\hline & Octadecylamine & PA-OCT & 85.69 \\
\hline \multirow{2}{*}{$\begin{array}{c}\text { Myristic acid } \\
228.38\end{array}$} & PEG 1000 & My-1000 & 90.11 \\
\hline & PEG 4000 & My-4000 & 89.12 \\
\hline \multirow{2}{*}{$\mathrm{CH} 3(\mathrm{CH} 2)_{12} \mathrm{COOH}$} & PEG 6000 & My-6000 & 87.98 \\
\hline & Stearyl alcohol & My-SA & 94.7 \\
\hline \multirow{2}{*}{$\mathrm{CH}_{3}\left(\mathrm{CH}_{2}\right)_{11} \mathrm{CH}_{2} \stackrel{\text { ll }}{\mathrm{OH}}$} & PEI & My-PEI & 97.33 \\
\hline & Octadecylamine & My-OCT & 85.55 \\
\hline
\end{tabular}

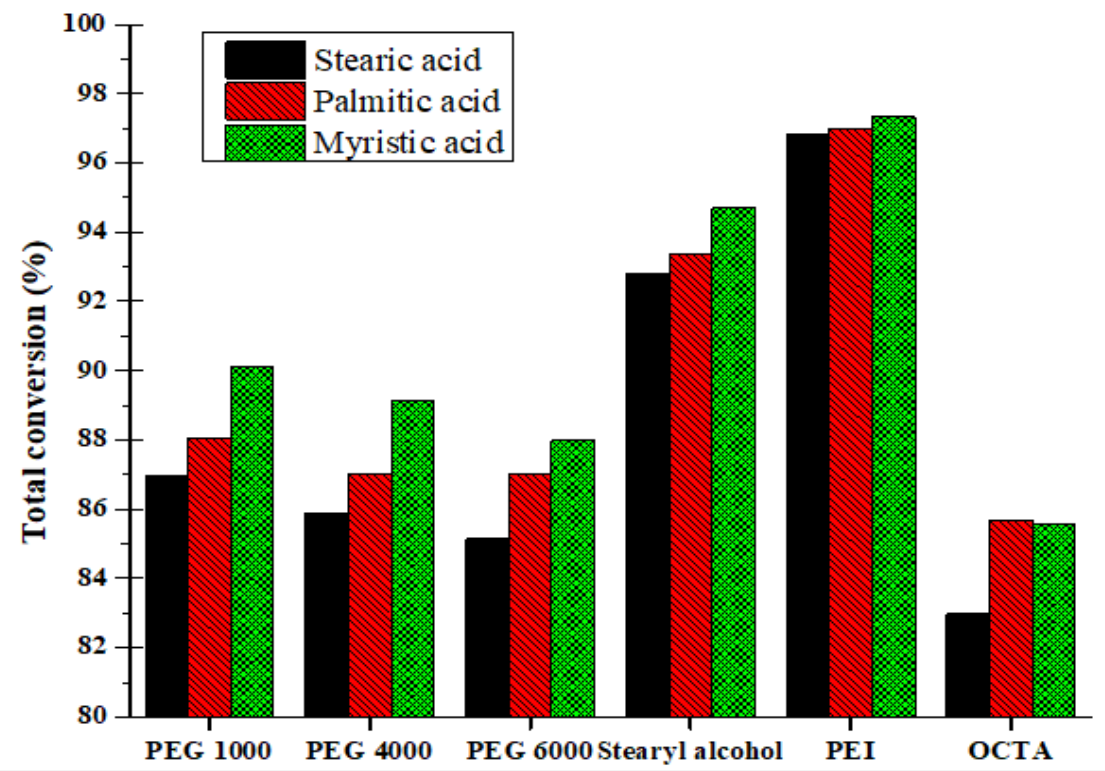

Figure 1: Total conversion percent of fatty acids derivatives.

The results provide that, increasing the molecular weight of fatty acid (carbon chain number) led to decreasing in the total conversion for the same alcohol or amine compound. Furthermore, this increasing in the total conversion may be due to the flexibility of the fatty acid, which give more opportunity to increasing the reaction between the reactant. In addition, the ability of formation amid group higher than to for ester group which make the reactivity of PEI and OCTA higher than using other compounds. 
HLB values and cloud point: The results for hydrophiliclipophilic balance (HLB) and cloud point presented in Table 2 and Figure 2 for the prepared materials with each saturated fatty acid. Whereas, HLB is an indication for the suitable usage for each prepared material. In addition, cloud point gives information for the suitable application temperature.

Table 2: HLB-number and the function expected for prepared materials from saturated fatty acids.

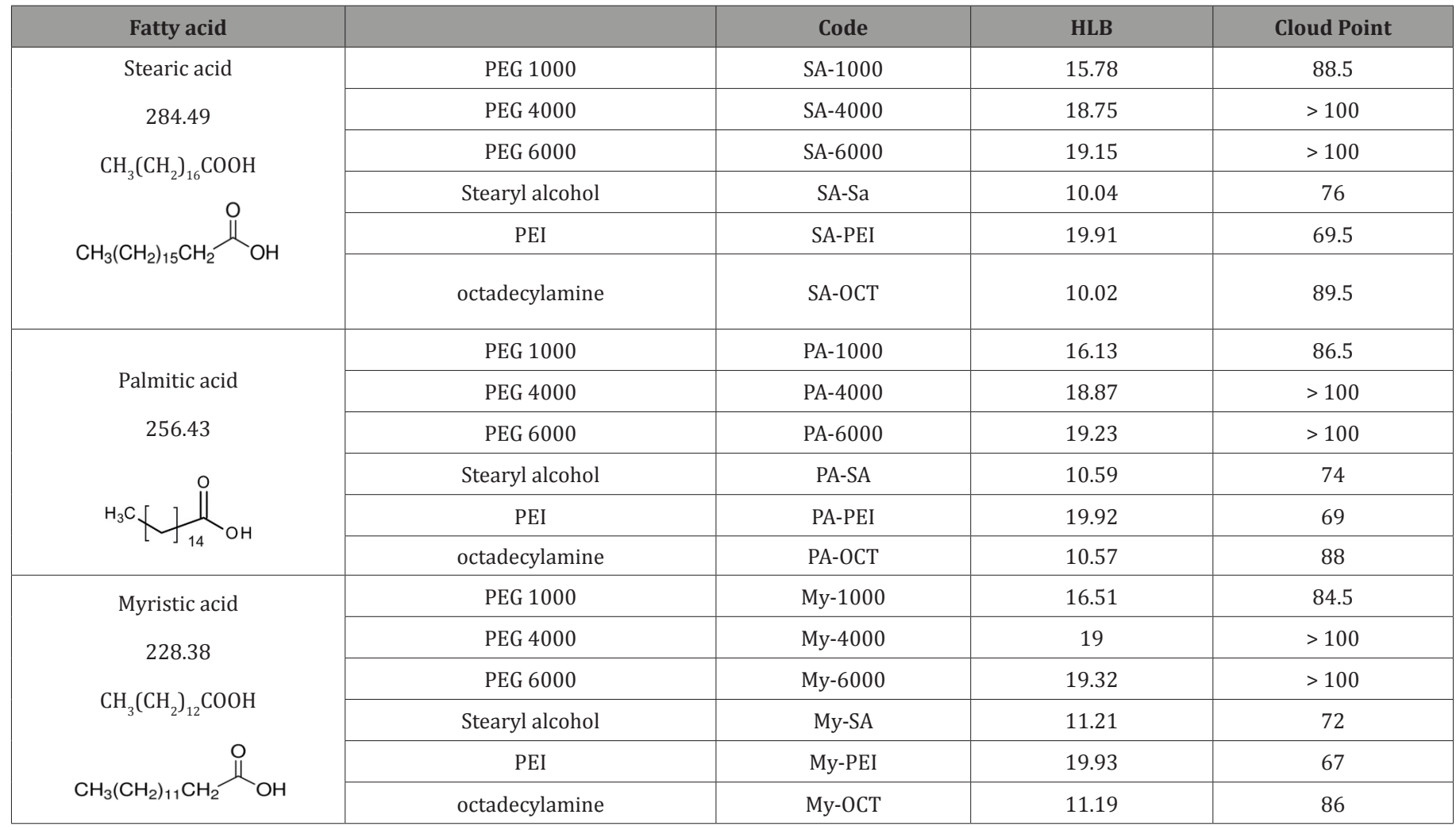
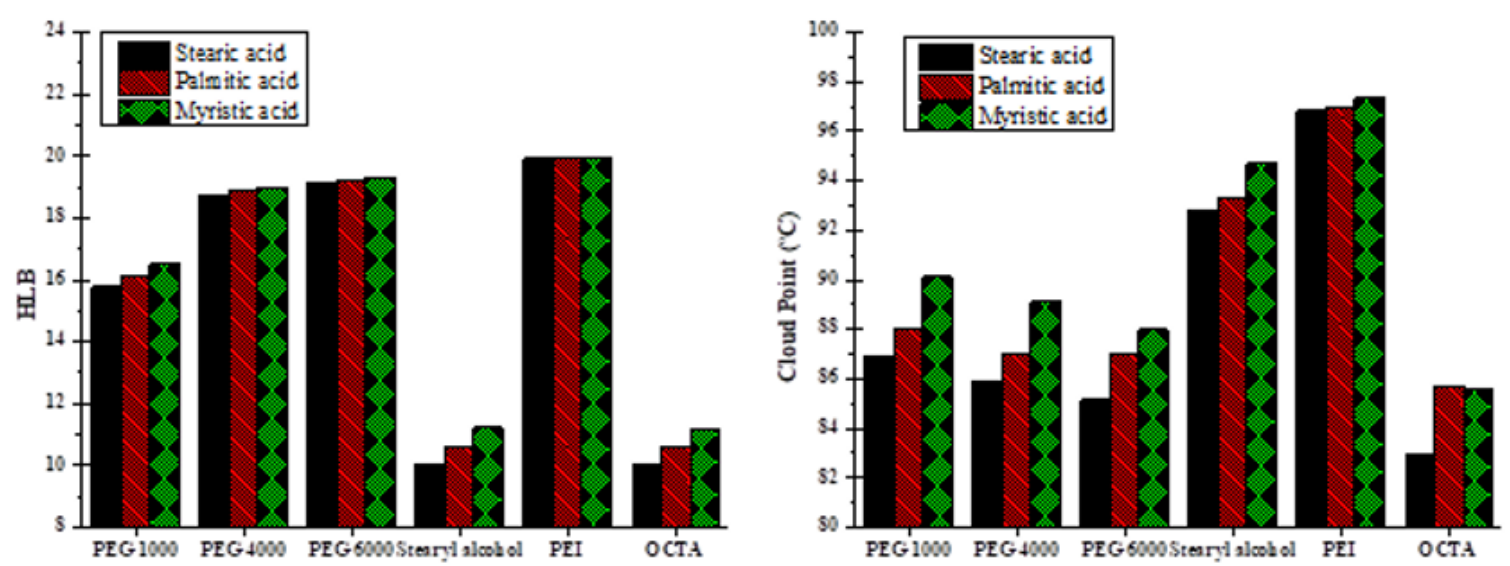

Figure 2: HLB and Cloud point of fatty acids derivatives.

Table 3: HLB-number and the function expected from the product in aqueous solution.

\begin{tabular}{|c|c|c|c|c|}
\hline HLB & Function & \multicolumn{3}{|c|}{ Suggested Product code } \\
\hline 1 to 3 & Anti-foaming agent & \multicolumn{3}{|c|}{-} \\
\hline 3 to 8 & W/O (water in oil) emulsifier & \multicolumn{3}{|c|}{ - } \\
\hline 7 to 9 & Wetting and spreading agent & \multicolumn{3}{|c|}{-} \\
\hline 13 to 16 & Detergent & & SA- 1000 & \\
\hline \multirow[t]{3}{*}{8 to 16} & O/W (oil in water) emulsifier & SA-1000 & & \\
\hline & & SA-Sa & PA-Sa & My-Sa \\
\hline & & SA-OCT & PA-OCT & My-OCT \\
\hline
\end{tabular}




\begin{tabular}{|c|c|c|c|c|}
\hline 16 to 18 & Solubilize or Hydrotrope & & PA-1000 & MA-1000 \\
\hline$>16$ & Softener & & PA-1000 & My-1000 \\
\hline & & SA-4000 & PA-6000 & My-6000 \\
\hline & & SA-6000 & PA-PEI & My-PEI \\
\hline
\end{tabular}

The results provide that, increasing the molecular weight of fatty acid cause decreasing the HLB and increasing the cloud point for the same alcohol or amine compound. HLB values of can be suggest the suitable function of each material based on the HLB. From the data in Table 3, it can conclude that:

a. Most of the produced materials, have HLB's ranging from 8 to 18 , these values are within the range of oil - in water $(\mathrm{o} / \mathrm{w})$ emulsifiers.

b. HLB's of SA-1000 was falls in the range recommended for detergents (i.e. the range of 12-16).

c. HLB's of MA-1000 and PA-1000 are fall in the range recommended for solubiliziers (i.e. the range of 15-18).

d. From another view most of the prepared materials having HLB values more than 16, it is expected that their behavior in aqueous solutions are mush similar to PEG 6000 rather than the parent fatty acids $[1,9]$. So, the unique structures of all these materials, allow them to confer textiles softening effect.

Table 2 and Figure 2 shows the cloud points of the prepared materials with fatty acids under investigation. It is clear that, for the same fatty acid, the cloud point increases upon increasing PEG molecular weight. This can be ascribed to the accompanying increase in both hydrophilicity and hydrogen bonding, which requires more energy to break the latter and separate the condensate in a cloudy form. Furthermore, for hydroxyl or amine compounds, increase the molecular weight of saturated fatty acid led to increase the cloud point of the produced materials.

FT-IR measurements: FT-IR spectra for all prepared materials are presented in Figure 3 for saturated fatty acid derivatives. Spectra of fatty acid have peaks at 1110, $2850-2930,2960-2960$ and 1670 - $1710 \mathrm{~cm}^{-1}$ represent the $\mathrm{C}-\mathrm{O}-\mathrm{C}, \mathrm{OH}, \mathrm{C}-\mathrm{H}$ and $\mathrm{C}=\mathrm{O}$ respectively $[1,9,12,29]$. Furthermore, spectra of prepared materials show ester band $(-0-\mathrm{C}=0)$ at $1730-1740 \mathrm{~cm}^{-1}$ which attributed to presence of carbonyl group resulted from the reaction between carboxyl and hydroxyl groups. This band was observed in spectra of fatty acids at $1670-1710 \mathrm{~cm}^{-1}$. In addition, a peak for OH group at $3390-3420$ $\mathrm{cm}^{-1}$ was observed in the spectra for produced material via material having dihydroxyl groups. Therefore, it can be concluded that, the ester group appears in the IR spectra of the condensates.
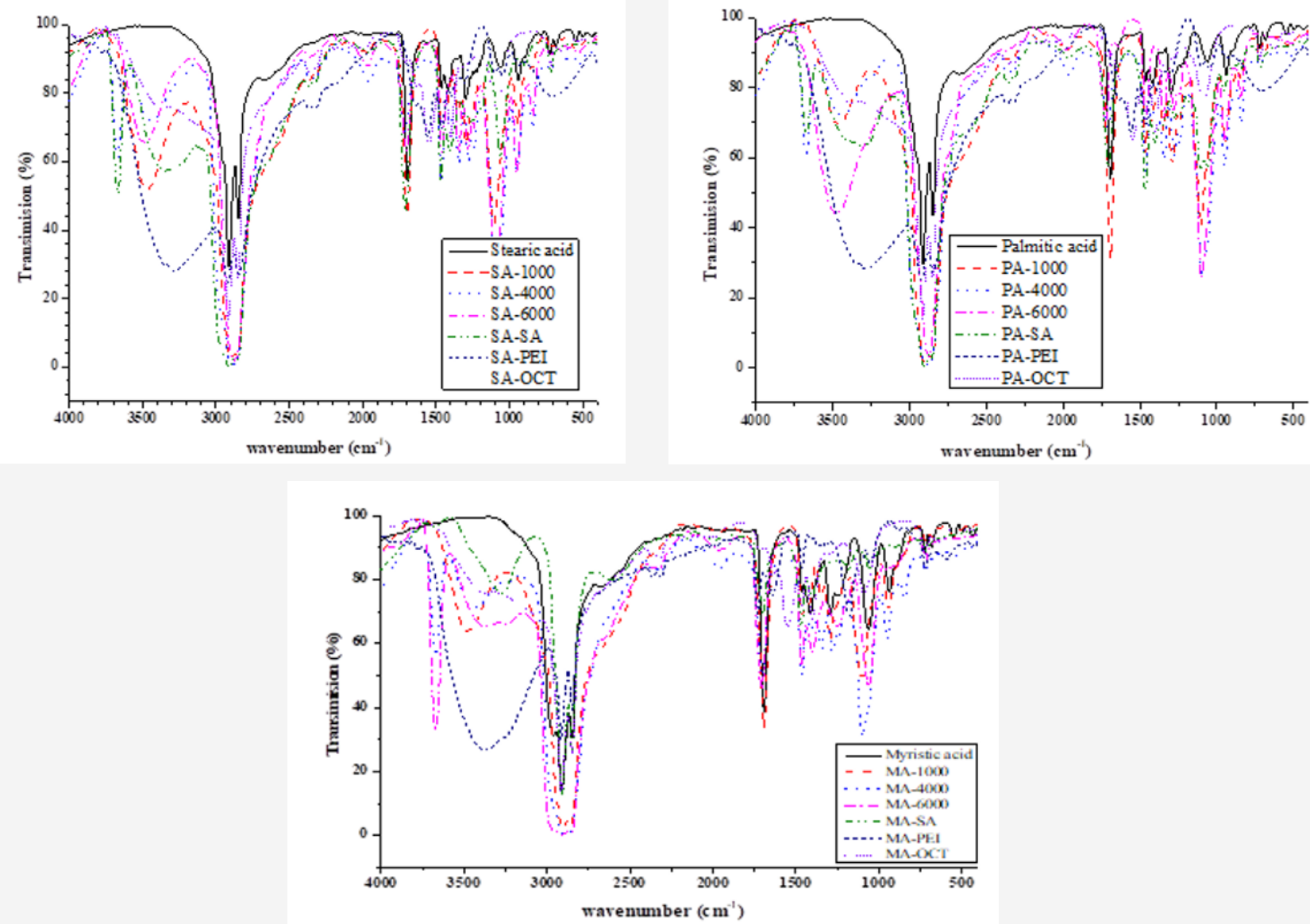

Figure 3: FT-IR spectra of saturated fatty acid and its derivatives. 
On the other side, spectra for produced materials from materials having amine group (PEI and OCTA) show presence of three main functional groups; $\mathrm{NH} 2, \mathrm{NH}$ and $\mathrm{CH} 2$ (at 2850 and $2960 \mathrm{~cm}^{-1}$ ) [30, 31]. In addition, there are two peaks appears at 1112 and 1645 $\mathrm{cm}^{-1}$, which they corresponding to stretching vibration of the C-N group and bending vibration of the NH group of PEI respectively. In addition, the FT-IR spectrum of prepared materials with PEI or OCTA, the absorption peaks including $(\mathrm{C}=0$, amide I and II $(\delta(\mathrm{NH})$; $1720,1550 \mathrm{~cm}^{-1}$ ) and (C-O-C, $1110 \mathrm{~cm}^{-1}$ ), were observed. Therefore, it can be concluded that, the amide group appears in the IR spectra of the condensates of fatty acid with amine compounds.

Table 4: Mechanical and physical properties of treated cotton fabrics.

\section{Prepared materials as auxiliaries for cotton fabric}

Prepared materials as softeners: Most of the prepared materials used as softener for cotton fabrics with three different concentration. Table 4 listed all the data about mechanical and physical properties of treated cotton fabrics. It is clear that, treated fabrics with prepared materials gained an enhancement in physical and mechanical properties in comparison with blank fabric. In addition, softening effect increase as increasing in the softener concentration. Wettability (means hydrophilicity) of the treated fabrics was reduced upon treatment, which noticeable provided at a concentration of 30 and $60 \mathrm{~g} / \mathrm{l}$ than at $10 \mathrm{~g} / \mathrm{l}$.

\begin{tabular}{|c|c|c|c|c|c|c|c|c|c|c|c|c|}
\hline \multirow{4}{*}{$\begin{array}{c}\text { Fatty } \\
\text { Acid Derivatives }\end{array}$} & \multicolumn{12}{|c|}{ Fatty Acid Derivatives Concentration } \\
\hline & \multicolumn{4}{|c|}{$10(g / l)$} & \multicolumn{4}{|c|}{$30(g / 1)$} & \multicolumn{4}{|c|}{$60(g / 1)$} \\
\hline & & S(mg. & CRA & $\mathbf{w}$ & $\mathbf{R}$ & $\mathbf{S}$ & CRA & w & $\mathbf{R}$ & $\mathbf{S}$ & CRA & $\mathbf{w}$ \\
\hline & конот) & cm) & $\left(\mathrm{W}+\mathrm{F}^{\circ}\right)$ & (sec) & $(\mu \mathrm{m})$ & (mg.cm) & $\left(\mathrm{W}+\mathrm{F}^{\circ}\right)$ & (sec) & $(\mu \mathrm{m})$ & (mg.cm) & $\left(\mathrm{W}+\mathrm{F}^{\circ}\right)$ & (sec) \\
\hline Blank & 20.3 & 26497 & 181 & 4 & 20.3 & 26497 & 181 & 4 & 20.3 & 26497 & 181 & 4 \\
\hline SA- 4000 & 18.2 & 18123 & 235 & 40 & 16.4 & 16123 & 240 & 60 & 14.7 & 14996 & 254 & 80 \\
\hline SA- 6000 & 19.3 & 16889 & 229 & 16 & 17.9 & 14889 & 235 & 40 & 16.4 & 13478 & 252 & 60 \\
\hline SA-PEI & 22.3 & 26751 & 252 & 3 & 20.7 & 23583 & 258 & 3 & 18.9 & 21348 & 273 & 3 \\
\hline PA-1000 & 18.3 & 17437 & 255 & 78 & 16.7 & 16112 & 269 & 99 & 14.2 & 14877 & 274 & 104 \\
\hline PA- 4000 & 18.5 & 16111 & 252 & 49 & 16.9 & 14987 & 267 & 69 & 14.9 & 14446 & 269 & 88 \\
\hline PA- 6000 & 18.9 & 14989 & 245 & 19 & 17.6 & 14103 & 251 & 27 & 16.6 & 13878 & 261 & 36 \\
\hline PA-PEI & 23.5 & 26512 & 271 & 3 & 21.9 & 24945 & 282 & 2 & 20.6 & 24547 & 288 & 2 \\
\hline My-1000 & 18.3 & 16112 & 256 & 77 & 17.8 & 16002 & 270 & 86 & 16.2 & 14476 & 279 & 90 \\
\hline My-4000 & 19.4 & 14974 & 251 & 49 & 18.4 & 14998 & 266 & 64 & 17.6 & 13213 & 275 & 67 \\
\hline My- 6000 & 20.1 & 14234 & 246 & 21 & 19.2 & 13876 & 252 & 28 & 18.3 & 12674 & 267 & 31 \\
\hline My-PEI & 25.1 & 26312 & 271 & 2 & 24 & 25650 & 283 & 1 & 22.9 & 23428 & 294 & 1 \\
\hline
\end{tabular}

R: Roughness, S: Stiffness, CRA: Crease Recovery Angle, W wettability

From another point of view, for the same fatty acid increase the molecular weight of PEG accompanied by increase in roughness with a drop-in stiffness and wettability. This observation is true also when increasing the molecular weight of fatty acid which accompanied by increased hydrophilicity of the produced materials.

Furthermore, reaction of fatty acid with compounds containing amine groups (PEI) led to increasing in the roughness and wettability with decreasing in stiffness properties of the treated fabrics. In addition, crease recovery angle for all treated fabrics with all produced materials from fatty acids with polyalcohol or amine have been enhanced.

Concerning to the concentration of produced materials, increased the concentration led to changing in the properties of treated fabrics with increasing or even decreasing according to the property.

Prepared materials as emulsifier for printing paste: Printing paste prepared using fatty acid derivatives as emulsifier were applied to cotton fabrics and then the printed fabrics were evaluated. Characteristics of the printed cotton fabrics (colour strength (K/S) and fastness properties) are presented in Table 5.

Table 5: colour strength and fastness properties of printed cotton fabrics.

\begin{tabular}{|c|c|c|c|c|c|c|c|c|c|c|}
\hline \multirow{4}{*}{ Fatty acid derivatives } & \multirow{4}{*}{$\mathbf{K} / \mathbf{S}$} & \multicolumn{9}{|c|}{ Fastness properties } \\
\hline & & \multicolumn{2}{|c|}{ Washing } & \multicolumn{2}{|c|}{ Rubbing } & \multicolumn{4}{|c|}{ Perspiration } & \multirow{3}{*}{ Light } \\
\hline & & \multirow{2}{*}{ St. } & \multirow{2}{*}{ Alt. } & \multirow{2}{*}{ Wet } & \multirow{2}{*}{ Dry } & \multicolumn{2}{|c|}{ Alkaline } & \multicolumn{2}{|c|}{ Acidic } & \\
\hline & & & & & & St. & Alt. & St. & Alt. & \\
\hline Commercial emulsifier & 3.75 & 3 & 4 & 2 & 2 & 4 & 4 & 4 & 4 & 5 \\
\hline SA-1000 & 4.91 & 4 & 5-Apr & $3-\mathrm{Feb}$ & 3-Feb & 4 & 4 & 5-Apr & 5-Apr & 5 \\
\hline SA-Sa & 4.83 & 4 & 4 & $3-\mathrm{Feb}$ & 3-Feb & 5-Apr & 5-Apr & 5-Apr & 5-Apr & 5 \\
\hline SA-OCT & 4.95 & 4 & 4 & 3-Feb & 3-Feb & 5-Apr & 5-Apr & 5-Apr & 5-Apr & 5 \\
\hline
\end{tabular}




\begin{tabular}{|c|c|c|c|c|c|c|c|c|c|c|}
\hline & 4.42 & 4 & 4 & 3-Feb & 3-Feb & 5-Apr & 5-Apr & 5-Apr & 5-Apr & 5 \\
\hline PA-Sa & 4.81 & 4 & 4 & 3-Feb & 3-Feb & 5-Apr & 5-Apr & 5-Apr & 5-Apr & 5 \\
\hline PA-OCT & 3.86 & 4 & 4 & 3-Feb & 3-Feb & 5-Apr & 5-Apr & 5-Apr & 5-Apr & 5 \\
\hline My-Sa & 4.77 & 4 & 4 & 3-Feb & 3-Feb & 5-Apr & 5-Apr & 5-Apr & 5-Apr & 5 \\
\hline
\end{tabular}

\section{St: Staining}

Alt: Alternation

From the data in Table 5, all printed fabrics using pastes with prepared emulsifiers have comparable colour strength (K/S value). In addition, all pastes with fatty acid derivatives as emulsifier, give rise to washing, perspiration and light fastness of all printed fabrics are comparable to that containing commercial emulsifier in printing paste. Furthermore, rubbing fastness (wet and dry) of all prints are moderate, a characteristic of pigment prints has the nearby rubbing fastness values as that of commercial one.

\section{Stability of the paste upon storing}

Evaluation of the stability of the printing paste upon time was studied by measuring the viscosity of the printing paste on different shear rate at different storing time. Table 6 listed the apparent viscosity for all printing paste upon different time (freshly

Table 6: effect of storing time on the viscosity of printing.

\begin{tabular}{|c|c|c|c|c|c|c|c|c|c|}
\hline \multirow{2}{*}{ Storing Time } & \multirow{2}{*}{$\begin{array}{l}\text { Shear Rate } \\
\text { (S-1) }\end{array}$} & \multicolumn{8}{|c|}{ Apparent Viscosity (poise) } \\
\hline & & Commercial emulsifier & SA-1000 & SA-Sa & SA-OCT & PA-Sa & PA-OCT & My-Sa & Мy-OCT \\
\hline \multirow{4}{*}{ Freshly Prepared } & 2 & 144.6 & 120.5 & 132.6 & 126.5 & 129.5 & 128 & 128.8 & 128.4 \\
\hline & 20 & 43.8 & 40.3 & 42.1 & 41.2 & 41.6 & 41.4 & 41.5 & 41.4 \\
\hline & 50 & 18.3 & 15.2 & 16.8 & 16 & 16.4 & 16.2 & 16.3 & 16.2 \\
\hline & 100 & 11.4 & 12.3 & 11.9 & 12.1 & 12 & 12 & 12 & 12 \\
\hline \multirow[t]{4}{*}{ After 7 days } & 2 & 190.6 & 187.7 & 189.2 & 188.4 & 188.8 & 188.6 & 188.7 & 188.7 \\
\hline & 20 & 57.7 & 62.8 & 60.3 & 61.5 & 60.9 & 61.2 & 61 & 61.1 \\
\hline & 50 & 24.1 & 23.7 & 23.9 & 23.8 & 23.8 & 23.8 & 23.8 & 23.8 \\
\hline & 100 & 15 & 19.2 & 17.1 & 18.1 & 17.6 & 17.9 & 17.7 & 17.8 \\
\hline \multirow[t]{4}{*}{ After 1 month } & 2 & 232 & 222.1 & 227.1 & 224.6 & 225.8 & 225.2 & 225.5 & 225.3 \\
\hline & 20 & 70.3 & 74.3 & 72.3 & 73.3 & 72.8 & 73 & 72.9 & 73 \\
\hline & 50 & 29.4 & 28 & 28.7 & 28.4 & 28.5 & 28.4 & 28.5 & 28.5 \\
\hline & 100 & 18.3 & 22.7 & 20.5 & 21.6 & 21 & 21.3 & 21.2 & 21.2 \\
\hline
\end{tabular}

\section{Conclusion}

Three different saturated fatty acid (stearic, palmitic and myristic acid) were reacted with six different materials having mono functional group (octadecylamine (amino group) and stearyl alcohol (hydroxyl group)) or bifunctional groups (polyethylene glycol 1000, 4000 and 6000) or polyfunctional groups (polyethyleneimine) at equimolar ratio, at $180^{\circ} \mathrm{C}, 8 \mathrm{~h}$. Percent total conversion was high (around 82.98 - $97.33 \%$ ). FT-IR spectra of produced materials proved the presence of ester or amide groups in the produced materials. HLB values provide that prepared materials can be used as different functional agents such $0 / W$ emulsifiers, detergents, solubilizers and softeners. Using prepared material to the suitable application in textile industries showing that, the suggesting material from HLB values using as emulsifier in $\mathrm{O} / \mathrm{W}$ emulsion have succeed to prepare a good printing paste with good prints characteristics (colour strength and colour prepared, after 7 days and one month) at different share rate. From the data, it is clear that, all prepared pastes are stable during investigated storing time without any phase separation. Regardless of shear rate, that all printing pastes have higher viscosity upon storing; by meaning that, the higher the storing time is the higher the apparent viscosity. This phenomenon is common in some polymeric thickening printing pastes, $[1,10]$ because of the better solubility and swelling of thickening agent over time. The increase in viscosity upon storing can be attributed to some changes in the paste internal structure, so that more hydrogen bonding can be formed between hydroxyl and amino groups of the fatty acid derivatives, with the external phases (water). Therefore, the binding between the two phases increases upon storing, leading to more resistance to flow $[1,10]$. fastness). Furthermore, suggesting material from HLB values using as finishing agents have succeed to use as finishing agent with very good physical and mechanical properties.

\section{Acknowledgement}

This project was supported financially by the National Research Centre (NRC), Egypt, project No. 11090127). Furthermore, the authors also gratefully grateful acknowledge to National Research Centre (NRC) for facilities provided.

\section{Conflict of Interest}

There is no conflict of interest.

\section{References}

1. Hassabo AG (2005) Preparation, characterisation and utilization of some textile auxiliaries. Textile Chemistry, El-Azhar University. 
2. Chemat F, Poux M, Galema SA (1997) Esterification of stearic acid by isomeric forms of butanol in a microwave oven under homogeneous and heterogeneous reaction conditions. J Chemical Society, Perkin Transactions 2 (11): 2371-2374.

3. Liu Y, Lotero E, Goodwin JG (2006) Effect of carbon chain length on esterification of carboxylic acids with methanol using acid catalysis. J Catalysis 243(2): 221-228.

4. Hassabo AG, Mendrek A, Popescu C, Keul H, Möller M (2014) Deposition of functionalized polyethylenimine-dye onto cotton and wool fibres. Res J Textile and Apparel 18(1): 36-49.

5. Demirci S, Sahiner N (2014) PEI-based ionic liquid colloids for versatile use: Biomedical and environmental applications. J Mol Liquids 194: 8592.

6. Liu Z, Wang Y, Zu Y, Fu Y, Li N, et al. (2014) Synthesis of polyethylenimine (PEI) functionalized silver nanoparticles by a hydrothermal method and their antibacterial activity study. Mater Sci Eng C Mater Biol Appl 42: 31-37.

7. Hassabo AG (2011) Synthesis and deposition of functional nanomaterials on natural fibers. RWTH Aachen University, Germany p. 153.

8. Pang Y, Zeng G, Tang L, Zhang Y, Liu Y, et al. (2011) PEI-grafted magnetic porous powder for highly effective adsorption of heavy metal ions. Desalination 281: 278-284.

9. Abo Shosha MH, El Sayed Z, Hassabo AG (2009) Preparation and characterizations of fatty acid / polyethylene glycol condensates and utilization as textile softeners. Res J of Textile and Apparel 13(2): 46-60.

10. Abo-Shosha MH, Nassar FA, Haggag KM, El-Sayed Z, Hassabo AG (2009) Utilization of some fatty acid/peg condensates as emulsifiers in kerosene paste pigment printing. Res J Textile and Apparel 13(1): 65-77.

11. ASTM D1980-87 (1998) Standard test method for acid value of fatty acids and polymerized fatty acids. ASTM International: West Conshohocken, $\mathrm{p}$. 227.

12. Abo-Shosha MH, Nassar FA, El-Sayed Z, Hassabo AG (2006) Preparation and characterizations of some fatty acid/polyethylene glycol condensates, in Egyptian first international conference in chemistry: chemistry for human needs in developing countries: Sharm El Sheikh, Egypt.

13. ASTM Standard Test Method C33 (ASTM D-2024-65), (2003) Standard test method for cloud point of nonionic surfactant. ASTM International: West Conshohocken, USA, p. 204

14. AATCC Test Method (66-1990), (1993) Wrinkle recovery of fabric: recovery angle method, in technical manual method American association of textile chemists and colorists. p.99.

15. ASTM Standard Test Method C33 (ASTM D-1388-08), (2012) Standard test methods for stiffness of fabrics. ASTM International: West Conshohocken, PA, USA.

16. AATCC Test Method (39-1971), (1971) Water repellency property of fabric. Technical manual method of the American association of textile chemists and colorists: USA.
17. Kubelka P, Munk F (1931) Ion exchange recovery of palladium (II) from nitrate weak acidic solutions. Z Tech Phys 12: 593-601.

18. Mehta KT, Bhavsar MC, Vora PM, Shah HS (1984) Estimation of the kubelka--munk scattering coefficient from single particle scattering parameters. Dyes and Pigments 5(5): 329-340.

19. Waly A, Marie MM, Abou-Zeid NY, El-Sheikh MA, Mohamed AL (2006) Process of single-bath dyeing, finishing and flam-retarding of cellulosic textiles in presence of reactive tertiary amines. $3^{\text {rd }}$ International Conference of Textile Research Division, NRC, Textile Processing: State of the Art \& Future Developments. Cairo, Egypt.

20. Waly A, Marie MM, Abou-Zeid NY, El-Sheikh MA, Mohamed AL (2008) Flame Retarding, Easy Care Finishing and Dyeing of Cellulosic Textiles in One Bath. Egyptian Journal of Textile Polymer Science and Technology 12(2): 101-131.

21. Waly AI, Marie MM, Abou-Zeid NY, El-Sheikh MA, Mohamed AL (2012) Processes of dyeing, finishing and flame retardancy of cellulosic textiles in the presence of reactive tertiary amines. Res J Textile and Apparel 16(3): 66 - 84

22. A. G. Hassabo, (2005) Preparation, Characterisation and utilization of some textile auxiliaries. El-Azhar University: Cairo, Egypt.

23. Hassabo AG, Erberich M, Popescu C, Keul H (2015) Functional polyethers for fixing pigments on cotton and wool fibers. Research and Reviews in Polymer 6(3): 118-131.

24. AATCC Test Method (61-2007), (2008) Colorfastness to laundering: accelerated, in American association of textile chemists and colorists, technical manual method American Association of Textile chemists and colorists. pp. 88-90.

25. AATCC Test Method (8-2007), (2008) Colorfastness to crocking Crockmeter method, in technical manual method American association of textile chemists and colorists. pp. 17-19.

26. AATCC Test Method (15-2013), (2013) Colour fastness to perspiration, in technical manual method American association of textile chemists and colorists. pp. 30-32

27. AATCC Test Method (16-2004), (2005) Colour fastness to light: outdoor in technical manual method American association of textile chemists and colorists. pp. 23-25

28. Cai Y, Pailthrope MT, David SK (1999) A new method for improving the dyeability of cotton with reactive dyes. Textile Res J 69(6): 440 - 446

29. Silverstein RM, Bassler GC, Morrill TC (1991) Spectrometric identification of organic compounds. ( $5^{\text {th }}$ edn), John Wily \& Sons New York, USA, p. 432.

30. Kurecic M, Sfiligoj Smole M, Stana Kleinschek K (2012) UV polymerization of poly ( $\mathrm{N}$-isopropylacrylamide) hydrogel. Materials and Technology 46(1): 87-91.

31. Yang T, Hussain A, Bai S, Khalil IA, Harashima H, et al. (2006) Positively charged polyethylenimines enhance nasal absorption of the negatively charged drug, low molecular weight heparin. J Control Release 115(3): 289-297. 